\title{
Barriers and Perception Towards Spectacle Wear among a Student Population of University of Buraimi, Oman
}

*Gopi S. Vankudre and Babu Noushad

\begin{abstract}
Objectives: The study aimed to evaluate the barriers and perceptions towards spectacle wear among the student population of the University of Buraimi, Oman. Methods: A descriptive, questionnaire-based and cross-sectional study was conducted between December 2017 and May 2018. Ophthalmic examination and a standard spectacle prescription protocol were used to identify those with inappropriate spectacle coverage. A selfdesigned and expert validated English-language questionnaire was utilised. A chi-square test was used to assess the association between the participants' types of perceptions and sociodemographic and refractive error-related profiles. Results: In total, 275 students participated in the study (response rate: 17.19\%) and 170 (61.8\%) were having inappropriate spectacle correction. Only $26 \%$ of them used spectacles since the majority ( $73.5 \%)$ had never had their eyes examined before this study. Most perceived spectacle wear positively (53.5\%), followed by some having negative (36.5\%) or neutral (10.0\%) perceptions. Those from a health science background including Nursing and Optometry had a higher positive perception towards spectacle wear than others $(P=0.012)$. The difference in the perception scores between myopic and hypermetropic refractive error groups was statistically insignificant $(P=$ 0.882). Conclusion: The majority of the participants had had inappropriate vision corrections with spectacles and not undergone any prior ocular examinations. Few wore spectacles; however, these were inappropriate given their current refractive status. The reasons for spectacle non-wear were that either new spectacles had been ordered or spectacles were lost or broken. It is recommended that the school eye health initiative be extended to the university level. A holistic eye-health promotional approach toward integrating students, teachers and parents into this initiative can improve spectacle wear within the studied population.
\end{abstract}

Keywords: Eyeglasses; Refractive Errors; Ametropia; Spectacles; Patient Compliance; Oman.

\footnotetext{
Advances in KNOWledge

The study's findings reveal that there is a positive perception of spectacle wear among a university student population in Oman.

This positive perception is more common among students from health science majors compared to others.

Despite having a positive perception, compliance towards spectacle wear is poor

Non-compliance towards the uptake of ophthalmic services was found to be the main barrier to spectacle wear.
}

\section{application to Patient Care}

The study's results stress the importance of extending the current school eye health initiative implemented in Oman to the university level.

Eye health promotional programmes that integrate students, teachers and parents, can improve spectacle wear and reduce the burden of avoidable blindness within the country.

A

CROSS THE WORLD, REFRACTIVE ERROR IS estimated to affect around 2.3 billion persons; $90 \%$ of the affected population in which this error remains uncorrected resides in developing countries. ${ }^{1}$ A recent systematic review on refractive errors in a Middle Eastern population over 15 years of age observed that the prevalence of myopia, hypermetropia and astigmatism is $30 \%, 21 \%$ and $24 \%$, respectively. ${ }^{2}$ Moreover, a study conducted among the medical student population in Saudi Arabia observed a predominance of myopic refractive error (53.7\%), followed by hyperopia (3.7\%) and astigmatism (1.2\%).
The study also raised concern about the increase in the incidence of refractive errors, especially myopia. ${ }^{3}$

The increasing prevalence of uncorrected refractive errors in the Middle East is becoming a primary public health issue. The studies that have been conducted among the low-income countries have observed that disadvantaged groups, such as those of a specific ethnicity and/or those belonging to lower socioeconomic or educational backgrounds and/or those having to bear the expenditure of spectacles from their own pocket, are at a higher risk of having non-correction of refractive errors. ${ }^{4}$ Despite 


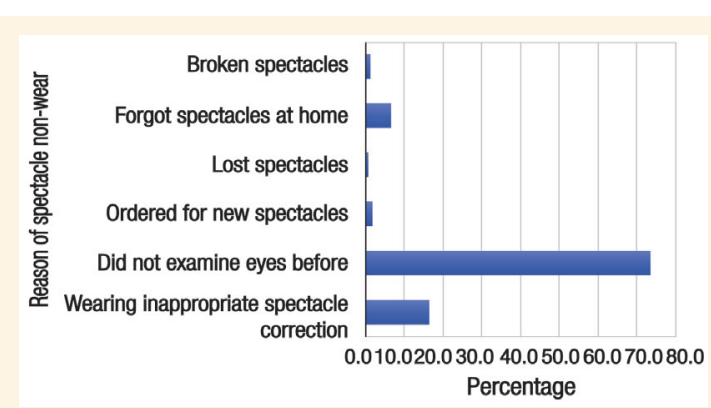

Figure 1: Distribution of reasons for spectacle nonwear among the study's participants who have refractive errors $(\mathrm{N}=170)$.

the aforementioned studies and their wide-ranging findings, barriers to refractive corrections have not been sufficiently studied, especially among the young adult population residing in a fast-developing and economically rich country such as Oman.

Spectacle compliance is referred to as the act of regularly wearing the spectacle correction prescribed to the individual. A previous study among the schoolgoing population in Oman observed spectacles compliance in $62 \%$ of participants in grade 7.5 In another study among Omani school children, older students demonstrated better compliance (79.1\%) compared to lower-grade students. ${ }^{6}$ Interestingly, compliance was higher among female students compared to male students. It was also higher among the myopic group (72.5\%) compared to other groups with refractive errors. ${ }^{6}$ Compliance with spectacle wear is affected by an individual's or society's beliefs about spectacle wear by children or young adults. For instance, in developing countries such as Africa, spectacle wear is believed to harm ocular health, reflecting poor spectacle wear compliance among this population. ${ }^{1}$

Non-correction of refractive errors adversely impacts affected individuals both physically and mentally. Uncorrected refractive error can adversely affect the quality of life, educational status and career opportunities as well as social interaction. ${ }^{1,2,4,6}$ Over time, this imposes an economic burden on the affected individual as well as on the public health system. ${ }^{2}$ Students wearing spectacles have improved vision and hence a better quality of life in this regard, compared to the non-wearing group. ${ }^{7}$ Spectacle-related barriers such as social stigma, associated spectacle related myths such as continuus spectacle uses, adverserly affecting the vision or 'sunken eyes', cost and cosmesis have been observed in previous studies to be prohibiting the user from wearing spectacles. ${ }^{8}$ Discomfort, damaged or lost spectacles and low amount of myopia were other identified barriers stated in previous studies. ${ }^{5,9}$ Despite the availability of a simple corrective modality such as spectacles, it is less commonly utilised due to the existing misconceptions and negative perception towards spectacle wear. ${ }^{10,11}$ Due to Oman's status as a high income country (compared to other low-income countries), the economic factor is not a significant barrier to spectacle coverage. Spectacle wear is shown to be directly associated with the level of understanding of refractive errors and the perceptions of the affected individuals towards spectacles. ${ }^{1}$

Regional studies on spectacle coverage have been conducted among various age groups, but not among young adults per se. The lifestyle, visual needs and priorities of university students are different from those of school students; the barriers applicable to school children cannot be generalised to university students. Uncorrected refractive errors within the population indicate an inadequacy of the eye healthcare system as a simple means for spectacle correction is now available. The incidence of refractive errors is increasing at an alarming rate. International Myopia Institute estimated $50 \%$ of myopia prevalence by the year 2050 from the current $30 \%{ }^{12}$ Correcting even a small amount of refractive error can significantly improve the quality of life and visual function. ${ }^{13}$ The World Health Organization (WHO) recommends regular evaluation of the magnitude of spectacle coverage within the population. ${ }^{14}$ It is also recommended to identify the barriers of spectacle coverage such as age, gender and socio-economic status to account for any demographic variable that may act as a barrier. The findings of the current study would support, in particular, the enhancement of the refractive error correction facilities that are being provided within the region at present and the overall eye health system in general. ${ }^{6}$

A majority of the previous studies on spectacle wear have been conducted among school children or teachers. The higher-education student population is more mature and are better decision-makers than the school student population. Therefore, the perceptions of these two groups towards spectacle wear cannot be directly compared. Furthermore, these need to be explored separately. ${ }^{1}$ Studies have found that spectacle wear is enhanced due to the wearer's positive perception. ${ }^{8,15}$ A study among a university student population in Saudi Arabia observed that the students were unaware of the importance of spectacle wear and their responsibilities towards spectacle correction. ${ }^{15}$ The study findings highlight the importance of educating the community about refractive error and its correction. Ultimately, this could aid the reduction of the burden related to refractive error. ${ }^{15}$ The findings of the current study can also help the university administration design and implement an 
Table 1: Association of characteristics and refractive error profiles and participants' perceptions towards spectacle wear $(\mathrm{n}=152)$

\begin{tabular}{|c|c|c|c|c|}
\hline \multirow[t]{3}{*}{ Characteristic } & \multicolumn{3}{|c|}{ n (\%) } & \multirow[t]{3}{*}{$P$ value } \\
\hline & \multicolumn{2}{|c|}{ Type of perception } & \multirow[t]{2}{*}{ Total } & \\
\hline & Negative & Positive & & \\
\hline \multicolumn{5}{|l|}{ Gender } \\
\hline Male & $\begin{array}{c}12 \\
(32.4)\end{array}$ & $\begin{array}{c}25 \\
(67.6)\end{array}$ & $\begin{array}{c}37 \\
(24.3)\end{array}$ & \multirow{2}{*}{0.234} \\
\hline Female & $\begin{array}{c}50 \\
(43.5)\end{array}$ & $\begin{array}{c}65 \\
(56.5)\end{array}$ & $\begin{array}{c}115 \\
(75.7)\end{array}$ & \\
\hline \multicolumn{5}{|l|}{ Study major } \\
\hline Optometry & $\begin{array}{c}17 \\
(44.7)\end{array}$ & $\begin{array}{c}21 \\
(55.3)\end{array}$ & $\begin{array}{c}38 \\
(25.0)\end{array}$ & \multirow{4}{*}{0.012} \\
\hline Nursing & $\begin{array}{c}5 \\
(16.7)\end{array}$ & $\begin{array}{c}25 \\
(83.3)\end{array}$ & $\begin{array}{c}30 \\
(19.7)\end{array}$ & \\
\hline Business & $\begin{array}{c}23 \\
(54.8)\end{array}$ & $\begin{array}{c}19 \\
(45.2)\end{array}$ & $\begin{array}{c}42 \\
(27.6)\end{array}$ & \\
\hline Engineering & $\begin{array}{c}17 \\
(40.5)\end{array}$ & $\begin{array}{c}25 \\
(59.5)\end{array}$ & $\begin{array}{c}42 \\
(27.6)\end{array}$ & \\
\hline \multicolumn{5}{|c|}{ Location of residency } \\
\hline Urban & $\begin{array}{c}46 \\
(43.4)\end{array}$ & $\begin{array}{c}60 \\
(56.6)\end{array}$ & $\begin{array}{c}106 \\
(69.7)\end{array}$ & \multirow{2}{*}{0.209} \\
\hline Rural & $\begin{array}{c}16 \\
(34.8)\end{array}$ & $\begin{array}{c}30 \\
(65.2)\end{array}$ & $\begin{array}{c}46 \\
(30.3)\end{array}$ & \\
\hline \multicolumn{5}{|c|}{ Father's literacy status } \\
\hline University level & $\begin{array}{c}15 \\
(40.5)\end{array}$ & $\begin{array}{c}22 \\
(59.5)\end{array}$ & $\begin{array}{c}37 \\
(24.3)\end{array}$ & \multirow{3}{*}{0.684} \\
\hline $\begin{array}{l}\text { High school } \\
\text { level }\end{array}$ & $\begin{array}{c}26 \\
(44.8)\end{array}$ & $\begin{array}{c}32 \\
(55.2)\end{array}$ & $\begin{array}{c}58 \\
(38.2)\end{array}$ & \\
\hline $\begin{array}{l}\text { Elementary } \\
\text { level }\end{array}$ & $\begin{array}{c}2 \\
(36.8)\end{array}$ & $\begin{array}{c}36 \\
(63.2)\end{array}$ & $\begin{array}{c}57 \\
(37.5)\end{array}$ & \\
\hline \multicolumn{5}{|c|}{ Mother's literacy status } \\
\hline University level & $\begin{array}{c}5 \\
(29.4)\end{array}$ & $\begin{array}{c}12 \\
(70.6)\end{array}$ & $\begin{array}{c}17 \\
(11.2)\end{array}$ & \multirow{3}{*}{0.530} \\
\hline $\begin{array}{l}\text { High school } \\
\text { level }\end{array}$ & $\begin{array}{c}21 \\
(39.6)\end{array}$ & $\begin{array}{c}32 \\
(60.4)\end{array}$ & $\begin{array}{c}53 \\
(34.9)\end{array}$ & \\
\hline $\begin{array}{l}\text { Elementary } \\
\text { level }\end{array}$ & $\begin{array}{c}36 \\
(43.9)\end{array}$ & $\begin{array}{c}46 \\
(56.1)\end{array}$ & $\begin{array}{c}82 \\
(53.9)\end{array}$ & \\
\hline \multicolumn{5}{|c|}{ Parent working in the medical sciences field } \\
\hline Yes & $\begin{array}{c}37 \\
(45.7)\end{array}$ & $\begin{array}{c}44 \\
(54.3)\end{array}$ & $\begin{array}{c}81 \\
(53.3)\end{array}$ & \multirow{2}{*}{0.190} \\
\hline No & $\begin{array}{c}25 \\
(35.2)\end{array}$ & $\begin{array}{c}4.6 \\
(64.8)\end{array}$ & $\begin{array}{c}71 \\
(46.7)\end{array}$ & \\
\hline \multicolumn{5}{|c|}{ Eye-health expenditure responsibility } \\
\hline $\begin{array}{l}\text { Government/ } \\
\text { insurance }\end{array}$ & $\begin{array}{c}59 \\
(43.4)\end{array}$ & $\begin{array}{c}77 \\
(56.6)\end{array}$ & $\begin{array}{c}136 \\
(89.5)\end{array}$ & \multirow{2}{*}{$\begin{array}{c}0.065 \\
\text { (Fisher's } \\
\text { Exact } \\
\text { test) }\end{array}$} \\
\hline Self & $\begin{array}{c}3 \\
(18.8)\end{array}$ & $\begin{array}{c}13 \\
(81.3)\end{array}$ & $\begin{array}{c}16 \\
(10.5)\end{array}$ & \\
\hline \multicolumn{5}{|c|}{ Refractive error status } \\
\hline Myopia & $\begin{array}{c}57 \\
(41.0)\end{array}$ & $\begin{array}{c}82 \\
(59.0)\end{array}$ & $\begin{array}{c}139 \\
(91.4)\end{array}$ & \multirow{3}{*}{0.858} \\
\hline Hypermetropia & $\begin{array}{c}5 \\
(38.5)\end{array}$ & $8(61.5)$ & $13(8.6)$ & \\
\hline Total & $\begin{array}{c}62 \\
(40.8)\end{array}$ & $\begin{array}{c}90 \\
(59.2)\end{array}$ & $\begin{array}{c}152 \\
(100)\end{array}$ & \\
\hline
\end{tabular}

evidence-based eye care protocol for students. Hence, this study aimed to evaluate the barriers experienced by an Oman-based university student population and their perceptions concerning spectacle wear. This evaluation aimed to obtain baseline evidence to forecast the future coverage of spectacles and health promotion activities that could facilitate spectacle wear compliance within the country.

\section{Methods}

A descriptive, questionnaire-based and cross-sectional study was conducted between December 2017 and May 2018 at the University of Buraimi, Oman. The entire university student population (1,600 students) that had registered for the spring 2017-18 semester from different majors, genders or socioeconomic regions were invited to partipate in the current study. Invitations were sent through their university email IDs as well as through messages in/through student groups. The Open Source Epidemiologic Statistics for Public Health Version 3.01 (Updated 6 April 2013; Centre for Disease Control and Prevention, USA) was used to calculate the sample size. It considered a confidence level of $95 \%$ and hypothesised a $10 \%$ spectacle compliance rate as observed in a previous study among the student population of a university. ${ }^{13}$ The minimum required sample size was estimated as 128.

All volunteering participants who had refractive error without any other ocular abnormality were included in this study. Equal preference was given to all the volunteering and eligible participants from different sociodemographic profiles. The eligibility of the study participants was confirmed through a thorough ophthalmic examination including a slitlamp examination. A standard spectacle prescription protocol as per the guidelines of the WHO was performed among eligible participants. ${ }^{6}$ Those with inappropriate spectacle coverage were further provided with a self-administered questionnaire to evaluate barriers related to spectacle wear and included in the analysis.

The questionnaire was developed through a comprehensive literature review. ${ }^{6,9,11}$ It consisted of three components. The first component collected information regarding the reason for spectacle nonwear at the time of the study. The second and third components collected the responses for perception towards spectacle wear related to utility and psychological factors, respectively; the element of utility consisted of five questions and the psychological component consisted of seven questions. Responses to questions were collected using a 5-point Likert scale. 
The content of the questionnaire was validated with the help of a group of experts. ${ }^{16,17}$ The validators responded to their agreement related to the appropriateness of the included questions through a dichotomous response $(0=$ unfavourable; $+1=$ favourable) for each item. Validator responses were collected individually. The questionnaires were recirculated among the same experts following modifications. A minimum $80 \%$ of the subject expert's agreement for each component ensured its validity.

The internal reliability of the questionnaire was assessed using Cronbach's alpha (0.76). The first 10 questionnaire responses for all the 12 questionnaire items were considered for internal reliability. The test-retest validity of the questionnaire was assessed using Pearson correlation coefficient $(r=0.83)$. Of the participants, 10 individuals who had filled the questionnaire during their first visit were selected randomly and were again contacted after 15 days. They were further asked to resubmit their responses using the same questionnaire. However, these participants were blinded to their previous answers and were also kept unaware of the need for their repeated questionnaire responses after 15 days.

As the questionnaire had negative statements related to spectacle wear, and the participants needed to respond on a scale of strongly disagree $(-2.00)$ to strongly agree $(+2.00)$, barrier scores of $>0$ were considered to indicate negative and $<0$ positive perception towards spectacle wear. The sum of these ordinal responses was noted as a barrier score. The minimum and maximum scores ranged from -24 to +24 , respectively. Responses with scores ranging from 1 to 24 and from -1 to -24 were categorised as negative and non-negative perceptions towards spectacle wear, respectively.

Shapiro-Wilk normality distribution tests were performed to identify the normality of the barrier score rated by the participants on a Likert scale. The Statistical Package for the Social Sciences (SPSS), Version 21 (IBM Corp., Armonk, New York, USA) was used for data analysis. The components of the questionnaire that included responses related to reasons for spectacle non-wear and components related to psychological aspects were analysed using descriptive statistics. A chi-square test was used to assess the association between the type of perception and the sociodemographic and refractive error profiles of the participants. Mann-Whitney U test was used to compare the perception scores between myopic and hypermetropic groups. Fisher's exact test was used to identify the association between the barrier score and one variable (eye-health expenditure responsibility).
The study obtained ethical permission from the Research and Ethics Committee of the College of Health Sciences, University of Buraimi, Oman. This study adhered to the Declaration of Helsinki. The study details were explained to all the participants who were also informed of their right to withdraw from the study without any consequence or explanation. The study did not involve any participants from vulnerable groups such as those belonging to a lower socioeconomic status and no monetary or nonmonetary benefits were given to the participants. All the study-related information was provided to the participants as a written document and consent was obtained from each involved participant.

\section{Results}

A total of 275 students agreed to partake in the study (response rate $=17.19 \%$ ). Of these, 170 (61.8\%) were identified as having had inappropriate spectacle correction. However, out of the 170 eligible participants, analysis was performed only for 152 participants, as one had mixed astigmatism and 17 had neutral perception; they were excluded from the analysis as the number was low.

Out of 170 participants who had inappropriate spectacle coverage, including the case of mixed astigmatism, 125 (73.5\%) had not had their eyes examined previously. Only 28 students (16.5\%) were wearing spectacles but the correction was inappropriate considering their existing refractive status [Figure 1]. Over half of the participants (53.5\%) had a positive perception towards spectacle wear, followed by negative (36.5\%) and neutral (10.0\%) perceptions.

The Shapiro-Wilk normality distribution test indicated non-normal distribution $(P<0.001)$ of the barrier scores among the study population. Out of the 152 participants, 62 participants $(40.8 \%)$ had a negative perception, whereas 90 participants (59.2\%) had a positive perception towards spectacle wear. Male students (67.6\%), the rural population (65.2\%), health science students including Nursing and Optometry $(83.3 \%)$ and those who financed their eye health expenditure themselves (81.3\%) had a positive perception towards spectacle wear. Pearson's chi-square test observed a significant relationship between the type of perception and the study major of participants $(P=0.012)$ [Table 1 ]. The Mann-Whitney $\mathrm{U}$ test results showed no statistically significant difference in the perception scores of myopic and hypermetropic groups $(\mathrm{U}=881, P=0.882)$ 


\section{Discussions}

This study aimed to identify the barriers and perceptions of the university student population towards spectacle wear. Nearly two-third (61.8\%) of the total participants had inappropriate spectacle corrections. Most of the participants with inappropriate spectacle coverage had not undergone ocular examinations (73.5\%) earlier, except for their routine school eye health screening programme. Further, $16.5 \%$ of these participants were wearing spectacles; however, these were inappropriate given their current refractive status. The other reasons for spectacle non-wear included the following: spectacles ordered $(1.8 \%)$ or spectacles lost $(0.6 \%)$ or broken $(1.2 \%)$. These findings are similar to the observations of Gogate et al., whose study included a school student population in India. ${ }^{11}$ Another study among school children in Oman observed an increased prevalence of myopia and astigmatism, which was unnoticed by the parents or school authorities due to its low magnitude. ${ }^{5}$ The lower uptake of spectacle wear among mild myopic cases could be because of the asymptomatic nature of the condition. ${ }^{5}$ Moreover, Megbelayin found that only $9.8 \%$ of the studied student population who had refractive error wore spectacles; $18.2 \%$ did not wear them because of the cost factor and $56.4 \%$ were ignorant of their refractive status. ${ }^{13}$ A study conducted among undergraduate students of Ghana observed that $66 \%$ of the population was not aware of the use of spectacles in relieving the ocular symptoms. ${ }^{1}$ In addition, appoximately half of the studied population (54.2\%) believed that wearing spectacles would create an impression of being visually handicapped. ${ }^{1}$ In contrast, Halim et al. found the refractive error prevalence among the school students as $15.9 \%$; $12.1 \%$ were not using any kind of correction. ${ }^{18}$ This highlights the higher prevalence of uncorrected refractive error within the current study.

The lesser spectacle compliance rate observed in this study is a matter of concern, especially given that a prior study among Omani school children who had refractive errors observed a higher spectacle compliance rate of more than 60\%. ${ }^{5,6}$ Interestingly, no participant of the current study was observed or reported to have undergone any refractive surgery and only $1.8 \%$ reported to be wearing contact lenses.

Moreover, most of the participants (53.5\%) had a positive perception towards spectacle wear, and only $36.5 \%$ had a negative perception. Another study, having a similar refractive error prevalence, but a higher spectacle wear rate (80\%) among the undergraduate student population in the Middle East, found that $42.2 \%$ of the participants believed that spectacle wear might cause further visual impairment or increase spectacle dependency. ${ }^{15}$ Teasing by peers in this regard was one of the common reasons for not wearing spectacles among the population below 30 years of age. ${ }^{6}$ Felix and Ebenezer study observed that $53.4 \%$ of the studied population believed that spectacle usage may lead to the eyes being pushed in and 66.9\% felt that spectacle usage was inconvenient. ${ }^{1}$ A study within an African student population stated that the misbeliefs of the students or their parents related to spectacle wear were associated with spectacle nonwear among the student population. ${ }^{19}$ In contrast to the negative perceptions observed in these studies, in a study conducted among the adult African population, $2.8 \%$ of the participants with refractive error preferred using spectacles because they caused an impression of intelligence among peers. ${ }^{20}$ The current fashion trends were also observed to be responsible for spectacle wear. ${ }^{20}$ In Felix and Ebenezer's study, 57.2\% of the studied population believed that spectacles made the individual look professional. ${ }^{1}$ As expected, the student participants in the current study who were majoring in health sciences had a positive perception of spectacle wear $(P=0.012)$. Hence, considering the higher positive perception towards spectacle wear, stressing the importance of spectacle correction and ensuring spectacle compliance would not pose a difficulty as there is already acceptance in the population of such an initiative.

The change in the compliance pattern and observed lower positive perception towards spectacle wear among female students in the current study, compared to the younger school-going population in a previous study within Oman, reflects a negative shift in the perception towards spectacle wear. ${ }^{6}$ This study uncovered the gender-wise and age-wise change in the behavioural pattern concerning spectacle wear.

Interestingly, this study observed that the mother's literacy level was associated with appropriate spectacle wear. Halim et al's study found that the level of education positively influenced spectacle wear within the community. ${ }^{18}$ However, their study was unable to ascertain the parent's education as a determinant for uncorrected refractive error. Moreover, their study also stated that the lower economic status of the parent was associated with a lower uptake of refractive correction among the population, which could be sublimated in the current study due to the higher socioeconomic status of the study population.

The findings of this study emphasise the need for robust eye health surveillance focusing on young adults of Oman. However, the proportional inclusion of students in future studies from different study 
majors and different universities within the region can support these study findings. Other reasons for noncompliance towards the uptake of ophthalmic services among the study participants (73.5\%) needs to be explored separately through a qualitative study approach. Such studies could also be helpful for the eye healthcare industry involved in refractive modalities such as ophthalmic lenses, refractive surgeries or contact lenses. The parameter of appropriate spectacle wear used in this study could be used as an indicator and is suggested to be applied in monitoring the eye health programme at a regional and national level. In addition, it is important to further explore the underlying barriers of spectacle wear. Etim et al. observed that inconvenience towards spectacle wear was one of the factors reducing the quality of life among a population with refractive error compared to other modalities such as contact lenses or refractive surgeries. ${ }^{20}$ As the eye healthcare system is evolving towards a holistic approach rather than alleviating the patient's symptoms, a similar approach needs to be implemented while providing a spectacle prescription addressing the patient's concerns. ${ }^{6,21}$

In line with the national goal of Vision 2050 set by Oman, and due to change in the ocular disease scenario from earlier infectious to non-infectious over the last few decades, revisions in the health system are needed.6,10,11,22 Moreover, as a member of the WHO's global eye health action plan 2014-19, there was a need to generate the evidence for the prevalence and the reasons of visual impairment and apply the costeffective strategies to achieve the goal of reduction in avoidable blindness by $25 \%$ by the end of $2019.6,20$ As observed in the current study's results, though a higher percentage of the population was found to have a positive perception towards spectacle wear, there is a scope for exploring and rectifying the factors contributing to having a negative perception. A prior study within Oman observed inadequate knowledge about the common ocular condition causing visual impairment among the Omani adult population, and a holistic approach is recommended to improve the national eye healthcare system output. ${ }^{6}$ Improving the knowledge level can positively change the perception of the community towards spectacle wear. Furthermore, eye health promotion activities focusing on spectacle compliance should also integrate the parent and teacher's role in increasing spectacle compliance. ${ }^{10,11}$ Based on the findings of this study, it is recommended to extend the current school eyescreening programmes to the university level.

\section{Conclusion}

A majority of the participants had inappropriate spectacle corrections and had not undergone any prior ocular examination. Very few participants wore spectacles; however, these were inappropriate, given their current refractive status. Reasons for not wearing spectacles were that new spectacles had been ordered or spectacles were lost or broken. Over half of the participants had a positive perception towards spectacle wear. This was higher among students with health-related majors. The study stresses the need to extend the current school eye health initiative within Oman, to the university level. A holistic eye health promotional approach integrating students, teachers and parents can help in improving spectacle wear within this population.

\section{CONFLICT OF INTEREST}

The authors declare no conflicts of interest.

\section{FUNDING}

No funding was received for this study.

\section{AUTHORS' CONTRIBUTION}

VGS conceptualised and designed the study. VGS developed the research proposal and performed the statistical analysis. NB verified the proposal and provided timely inputs throughout the research process. Both the authors discussed the results and contributed to the drafting of the manuscript. Both authors approved the final version of the manuscript.

\section{References}

1. Felix AM, Ebenezer E. Attitudes and beliefs of undergraduate students to spectacle wear. Optom 2017; 2:1-4. https://doi. org/10.4172/2476-2075.1000123.

2. Khoshhal F, Hashemi H, Hooshmand E, Saatchi M, Yekta A, Aghamirsalim M, et al. The prevalence of refractive errors in the Middle East: A systematic review and meta-analysis. Int Ophthalmol 2020; 40:1571-86. https://doi.org/10.1007/s10792-020-01316-5.

3. Al-Rashidi SH, Albahouth AA, Althwini WA, Alsohibani AA, Alnughaymishi AA, Alsaeed AA, et al. Prevalence refractive errors among medical students of Qassim University, Saudi Arabia: Cross-sectional descriptive study. Open Access Maced JMed Sci 2018;6:940-3.https://doi.org/10.3889/oamjms.2018.197.

4. Johnson GJ, Minassian DC, Weale RA, West SK, Gower EW, Kuper $\mathrm{H}$, et al. The Epidemiology of Eye Disease, 3rd ed. London; Imperial College Press, 2012.

5. Al Harby S, Al-Asbali T, Khandekar R. Visual acuity and refractive status of Omani students with refractive error in grades 1,4 and 7: A retrospective cohort study. Oman J Ophthalmol 2016; 9:27-31. https://doi.org/10.4103/0974-620X.176097.

6. Khandekar R, Mohammed AJ, Al Raisi A. Compliance of spectacle wear and its determinants among schoolchildren of Dhakhiliya region of Oman: A descriptive study. J Sci Res Med Sci 2002; 4:39-43. 
7. Khandekar RB, Gogri UP, Al Harby S. The impact of spectacle wear compliance on the visual function related quality of life of Omani students: A historical cohort study. Oman J Ophthalmol 2013; 6:199-202. https://doi.org/10.4103/0974-620X.122278.

8. Kobia-Acquah E, Essien E, Ablordeppey R, Donkor R, AnkamahLomotey S, Nartey A. Attitudes and beliefs of undergraduate students to spectacle wear in Ghana. AOVS 2018; 8: 00264. https://doi.org/10.15406/aovs.2018.08.00264

9. Marmamula S, Narsaiah S, Shekhar K, Khanna RC. Presbyopia, spectacles use and spectacle correction coverage for near vision among cloth weaving communities in Prakasam district in South India. Ophthalmic Physiol Opt 2013; 33:597-603. https://doi.org/10.1111/opo.12079.

10. Al-Rashidi SH, Albahouth AA, Althwini WA, Alsohibani AA, Alnughaymishi AA, Alsaeed AA, et al. Prevalence refractive errors among medical students of Qassim University, Saudi Arabia: Cross-sectional descriptive study. Open Access Maced J Med Sci 2018; 6:940-3. https://doi.org/10.3889/oamjms.2018.197.

11. Gogate P, Mukhopadhyaya D, Mahadik A, Naduvilath TJ, Sane S, Shinde A, et al. Spectacle compliance amongst rural secondary school children in Pune district, India. Indian J Ophthalmol 2013; 61:8-12. https://doi.org/10.4103/0301-4738.99996.

12. Sankaridurg P, Tahhan N, Kandel H, Naduvilath T, Zou H, Frick KD, et al. IMI Impact of myopia. Invest Ophthalmol Vis Sci 2021; 62:2. https://doi.org/10.1167/iovs.62.5.2

13. Megbelayin EO. Barriers to uptake of prescribed refractive spectacles amongst Nigerian students. Int Res J Basic Clin Stud 2013; 1:71-7.

14. World Health Organization. Universal Eye Health: A Global Action Plan 2014-2019. From: www.who.int/blindness/AP2014 19_English.pdf?ua=1 Accessed: Aug 2020.
15. FK A, AG M, SM G, H K, HHA M, MR P. Attitude of female undergraduates towards spectacle correction of refractive errors. COJ Nurs Healthcare 2018; 4:422-6. https://doi.org/10.31031/ COJNH.2018.04.000588.

16. Jacobsen K. Introduction to Health Research Methods: A Practical Guide, 1st ed. Burlington, Massachusetts; Jones \& Bartlett Learning, 2014.

17. Bolarinwa OA. Principles and methods of validity and reliability testing of questionnaires used in social and health science researches. Niger Postgrad Med J 2015; 22:195-201. https:// doi.org/10.4103/1117-1936.173959.

18. Halim A, Suganda R, Sirait SN, Memed FK, Syumarti, Rini M, et al. Prevalence and associated factors of uncorrected refractive errors among school children in suburban areas in Bandung, Indonesia. Cogent Med 2020; 7:1737354. https://doi.org/10.108 0/2331205X.2020.1737354

19. Alrasheed SH, Naidoo KS, Clarke-Farr PC. Attitudes and perceptions of Sudanese high-school students and their parents towards spectacle wear. Afr Vis Eye Health 2018; 77. https://doi. org/10.4102/aveh.v77i1.392.

20. Etim BA, Oraegbunam NH, Ibanga AA, Okonkwo SN. Perception of refractive errors and impact of corrective treatments on adult patients seen at a tertiary health institution in South-South Nigeria. J Adv Med Medical Res 2018; 27:1-11. https://doi.org/10.9734/JAMMR/2018/45194.

21. Al-Mujaini AS. Knowledge, attitudes, and practices related to common eye diseases among the Omani population: How far have we come? Oman Med J 2020; 35:e96. https://doi. org/10.5001/omj.2020.14

22. Sultanate of Oman, Ministry of Health. Health Vision 2050. From: www.moh.gov.om/documents/16506/119833/Health+Vi sion+2050/7b6f40f3-8f93-4397-9fde-34e04026b829 Accessed: Apr 2020. 